\title{
Comparision of dynamic and static balance in adolescents handball and soccer players
}

\author{
Zeynep Inci KARADENIZLI ${ }^{1}$, Oya ERKUT ${ }^{1}$, Nusret RAMAZANOGLU1, \\ Selda UZUN ${ }^{1}$, Asiye Filiz CAMLIGUNEY ${ }^{1}$, Sinan BOZKURT ${ }^{1}$, \\ Cetin TIRYAKI ${ }^{1}$, Veysel KUCUK ${ }^{1}$, Bilsen SIRMEN²
}

\footnotetext{
${ }^{1}$ Marmara University School of Physical Education and Sport, Istanbul, Turkey.

${ }^{2}$ Esenyurt University Faculty of Health Science, Istanbul, Turkey.

Address correspondence to Z. Inci Karadenizli, incik72@gmail.com.
}

\begin{abstract}
This study aims to compare the static and dynamic balance in adolescents' handball and soccer players. 32 male student national athletes: soccer $(\mathrm{N}=17)$, handball $(\mathrm{N}=15)$ between $15-18$ years of age and at least 3 training years were included to the study. Assessment of static and dynamic balance was measured with Prokin 5.0 Technobody. There were no significant differences found between handball and soccer players on static and dynamic balance tests. We think that there are similar movements used often by both group, like faking and changing direction. On the other hand, there was found significant difference between right and left leg of soccer players perimeter scores for unipedal (Forward-Backward) dynamic balance slalom tests, when were compared within each group $\{\mathrm{t}(15)=-3,158, \mathrm{p}<0,01\}$. Unipedal (F-B) dynamic balance slalom tests score of right leg was better than left leg for soccer players, but, there were no significant differences for handball players $(p>0,05)$. All of the soccer players are dominantly using their right leg. In addition, this result might relate training methods and years, experience, muscle force asmmetry. On the other hand, handball players's dominant legs are also right, but their usually jumping legs are left.
\end{abstract}

Keywords: Static balance, dynamic balance, soccer, handball.

\section{INTRODUCTION}

Balance is generally defined as the ability to maintain the body's center of gravity within its base of support and can be categorized as either static or dynamic balance. Static balance is the ability to sustain the body in static equilibrium or within its base of support. Dynamic balance is supported to be more challenging because it requires the ability to maintain equilibrium during a transition from a dynamic to a static state. Both static and dynamic balance require integration of visual, vestibular, and proprioceptive inputs to produce an efferent response to control the body within its base of support $(25,33)$. There are findings that better balance ability of the players is the result of the ability of paying attention to the proprioseptive and visual clues (4).

Sport training can improve sensorimotor performance and postural control $(1,44)$ and may cause different balance abilities and these differences could be objectively measured using Center of Pressure Measurements (C.o.P) (19). In short, there are findings that prove the effect of changings both on motor system and sensory system to balance performance. Due to this, there should be sensor-motor periods at different levels to realize the motor abilities on special to each sport branches. The postural changings differ depending on sport exercises. For example, during judo trainings information recieved from somatosensory system is needed more and during dance training information recieved from visual system is needed more (27). The dinamic balance is important in fencing. During the acting of motor abilities on high speed, it is needed balance control and also high level visual control $(47,49)$. Although, at shooting the static balance is important and postural sway is needed to be controled. With an other example, mountain bikers need more somato-kinestetic information to reply with fast motor acts, and road bikers need more visual informations (23).

Dynamic balance, particularly on one leg, is therefore expected to be superior in taekwon-do practitioners than in the general population. Indeed, the ability to maintain single-leg standing balance is crucial in taekwon-do competitions (42). Lower limb 
joint proprioception is known to play a key role in maintaining normal body posture (18) and can be strengthened by training in judo, golf or tai chi (43). The dynamic balance on one leg is also very important for doing the basic movements on soccer and handball (not as much as taekwon-do for sure). Improving the different technical movements and kicking ball on soccer is needed the standing on one leg posture. Although, it is important to stabilise the standing leg to kick the ball as much as in a right position. For this reason, the postural control of the soccer players are evaluated during standing on one leg due to the specific situations of soccer (41). Soccer players often perform lower extremity passing, shooting and dribbling skills while wearing cleated or noncleated shoes on varieble turf conditions (26). It was reported significant correlations between medio-lateral ground reaction forces and maximum kicking velocity on the dominant kicking leg but not the non-dominant kicking leg in skilled soccer players (7). Because kicking movements place considerable demands on balance control $(11,10)$. This knowledge is the same for handball. A handball player is a jumper, thrower, sprinter all in one and must execute these skills with precision and speed. Motor ability, sprinting, jumping, flexibility and throwing velocity represent physical activities are more important for team handball. Handball players often perform upper extremity passing, shooting and dribbling skills while wearing shoes on flat, stiff surfaces. Their skills require great joint accelerations from jump landings and cutting maneuvers (32).

Throwing and kicking movements (in team handball and soccer) are considered as important aspects of the game and contribute to the high performance of the team. Researchers have also argued that balance is vital to the performance of fundamental motor skills like throwing, kicking, jumping, striking, hopping and skiping $(3,46,48)$. The literature does not enough knowledge for discriminating between two groups of athletes with postural balance. Atlethes's balance ability and postural control could be effected by kind of sport, different training methods and experience for team sports. For this reason, the current study is planned that compare static and dynamic balance belongs to soccer and handball players.

\section{MATERIAL \& METHOD}

\section{Participants}

Thirty two male student national athletes: Soccer $(n=17)$, handball $(n=15)$ between $15-18$ years of age and at least 3 training years were included to the study. The study was performed during competitive season. Participants were excluded if they had a lower extremity injury, vestibular problems and visual problems in the 6 months before the study. Before testing began, the aim and procedures of the study were explained to the participants and informed consent was obtained. Subjects were restrained from fatiguing exercise before test days. Balance test in university laboratory were conducted. The study was approved by the local Ethical Committee of Marmara University (Mar-YC-30.10.2007-0242).

\section{Procedures}

The measurements of the weight and height were done with Desis weighting expert digital weighting scale and linear measurement scale. Body mass index (BMI) was calculated as weight / height squared $\left(\mathrm{kg} / \mathrm{cm}^{2}\right)$.

For measuring leg strength, Leg dynamometer (back-leg dynamometer Takai, Tokyo, Japan) was used. After a 5-minute warm-up exercise, the subjects stood on a platform with their feet apart at a comfortable distance of shoulder width for balance. Their hands grasped each end of a bar. The subject was asked to flex at their knees to approximately 135 degrees. The back was kept straight and the hips were positioned direcly over the ankle joints. In this way, the activation of back muscles was eliminated. The chest was kept forward and the head was held in an erect position. The subject took in a large breath and slowly exhaled as they attempted to extend their knees smoothly and as forcefully as possible. Three attempts were made and a best score was recorded (37).

Static and dynamic balance measurements were measured by using Prokin 5.0 (Prokin System 5.0 Pk-Manop-05-en-01 Bergamo, Italy). After explaining the tests to the subjects, data were entered (height, weight, age) and the device was calibrated. The feet of the subjects were placed on the balance platform nakedly (in a fashion that the distance between feet was 10 centimeters and the projection of the maximum point of the medial arcs was on the $x$-axis). The subjects were asked to look at the screen in front of them with $10 \mathrm{~cm}$ distance 
between their feet while their arms were at sides, and to keep them fixed at (0) point. After completion of each test, when the device was being recalibrated, the subject was asked to sit down and rest. At the time of the measurements, no verbal feedback was given to the subjects other than what was necessary (http://www.tecnobody.it).

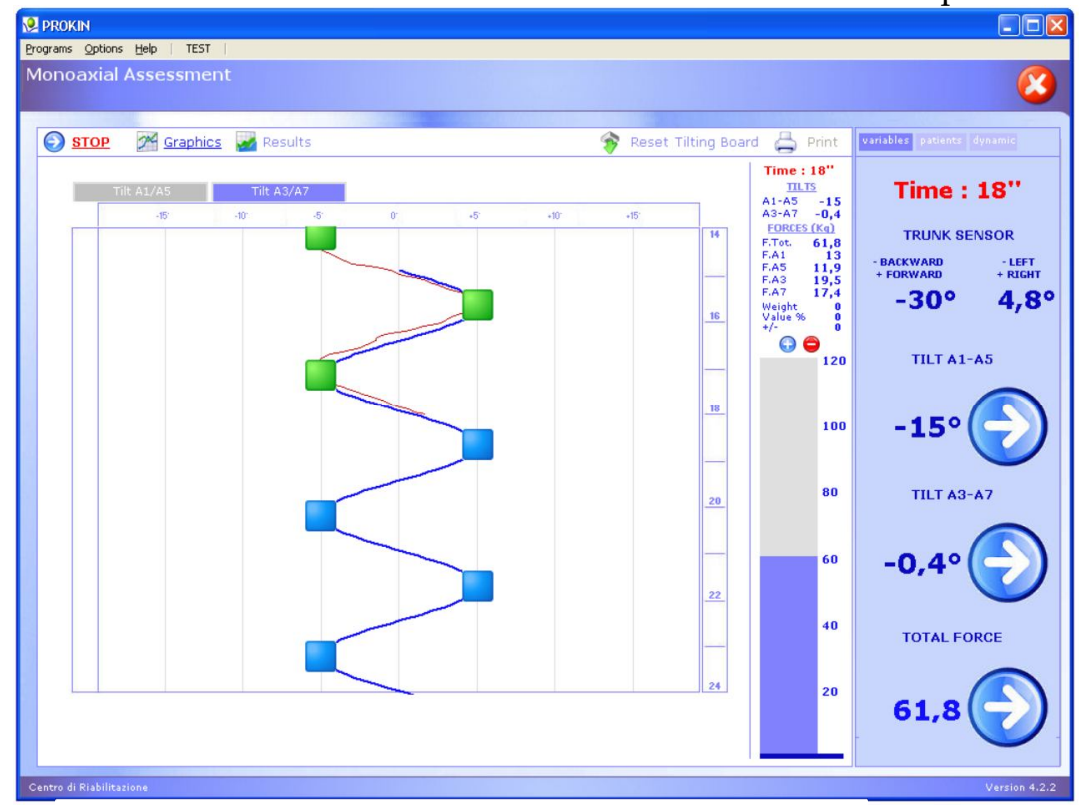

Figure 1. Dynamic balance slalom (medio-lateral) test.

Static Balance Test: Bipedal static balance were performed for 30 seconds with eyes open (EO) and eyes closed (EC). The data obtained were evaluated in terms of average center of pressure $X$ (C.o.P. $X$ ), average center of pressure $\mathrm{Y}$ (C.o.P. Y), forwardbackward standart deviation, medium-lateral standart deviation, average forward-backward

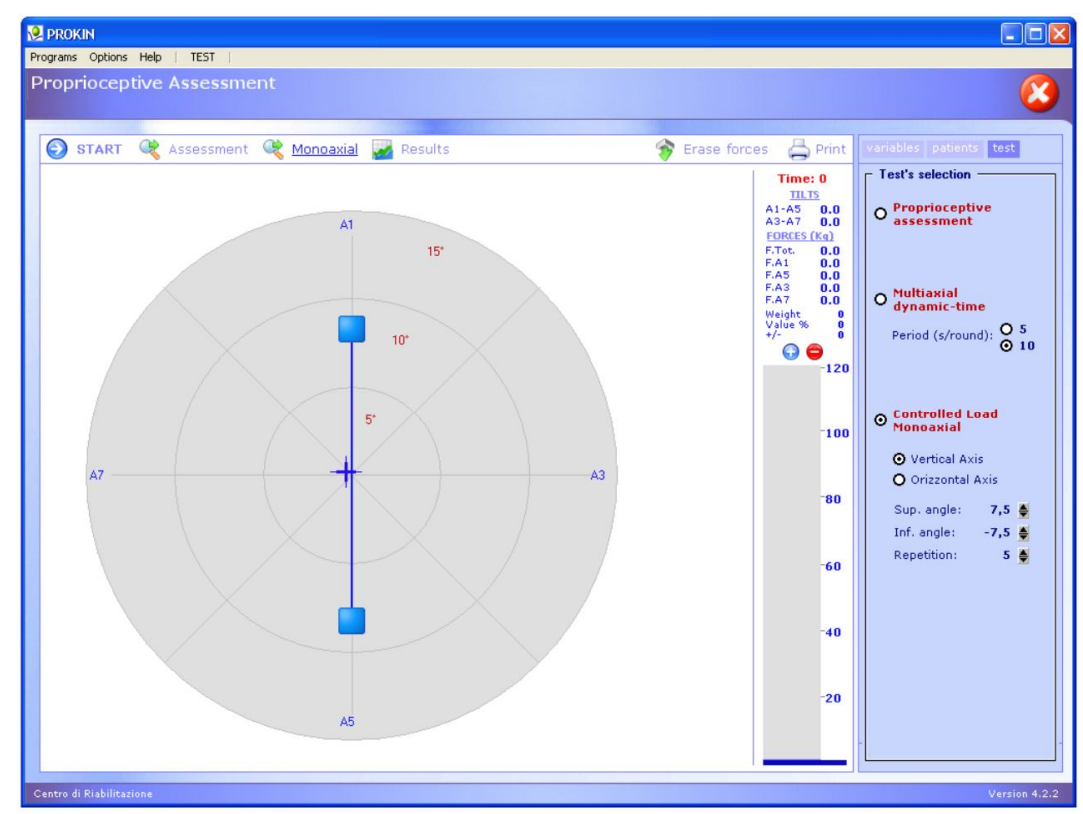

Figure 2. Forward-backward unipedal dynamic tests. velocity, average medium-lateral velocity, perimeter error, ellipse area, Romberg test perimeter ratio (RTPR) and Romberg test area ratio (RTAR).

Dynamic Balance tests: 1) Slalom test was used as monoaxial dynamic-time test Medio-Lateral (M-L) to one axis a time and to assess the subject's skill to complete the exercise. In this test, the subject tries to against. The subject's scope is to hit objectives and follow ideal line within 60 sn duration (a) hold with two hand and (b) without hold. Subject load was selected 5 hard degree (according to soft (0) to hard (10) degree system) (Figure 1 ).

2) Forward-Backward Unipedal dynamic-stance tests, were done with the controlled load monoaxial test (FB) for right and left foot. This test consists in a test where the subjects try to catch up two objectives with 10 repetitions on an axis controlling load (5 hard). Data obtained were evaluated in terms of right leg perimeter and left leg perimeter error $(\mathrm{mm}, \%)$ (Figure 2).

\section{Statistical Analysis}

Balance test evaluations between two groups compare with Independent $t$ test. Balance test evaluations within each group compare with Paired $\mathrm{t}$ test. SPSS Ver. 15.0 program was used for Statistical analysis.

\section{RESULTS}

Static Balance Test: There were no significant differences between two groups (handball and soccer) on static balance tests (Eyes open (EO) and closed eyes (EC); Average C.o.P. X, Average C.o.P. Y, Forward-Backward (F-B) Std. Dev., Medium-Lateral (ML) Std. Dev., Average F-B Velocity, Average M-L Velocity, Perimeter error, Elipse area). In addition, there were no significant differences between two groups on Romberg Test (EC/EO Perimeter Ratio and EC/EO Area Ratio) ( $p>0,05)$.

Dynamic Balance Test: There were no significant difference on dynamic balance slalom tests (both holding with hands and 
without holding hands), and unipedal dynamic balance test between handball and soccer players ( $p>0,05)$. Within each group is compared that it were found significant differences in perimeter error of slalom between with holding hands and without holding hands $\{\mathrm{t}(55)=4.553, \mathrm{p}<0.01\}$ (soccer), $\{t(58)=5.584, p<0.01\}$ (handball).

Within each group is compared that perimeter scores for unipedal (F-B) dynamic tests between right and left leg. For soccer players, significant differences were found between right and left leg $\{\mathrm{t}$ $(15)=-3,158, p<0,01\}$. Unipedal (F-B) dynamic balance test score of left leg was greater than right leg for soccer players $(p<0.05)$, but, there is no significant differences for handball players $(\mathrm{p}>0.05)$ (Table 2).

There were found significant differences on left leg mass and right leg mass between handball and soccer players. For left leg $\{t(97)=-2.97, p<0.01\}$, for right leg $\{t(34)=3.34, p<0.01\}$. Both left and right leg mass of handball players were greater than soccer players $(\mathrm{p}<0.05)$ (Table 3$)$.

\section{DISCUSSION}

Balance is vital to the performance of fundamental motor skills like throwing, kicking, jumping, striking, hopping and skiping $(3,46,48)$. The frequency of one-legged stance and two-legged stance differs considerably among sports.

One of the findings in our study that there were no significant differences on static and dynamic slalom balance tests between handball and soccer players $(p>0.05)$. Descriptive data and all balance tests were compared each other and it were not found significant differences between handball and soccer players $(\mathrm{p}>0.05)$.

Table 2. Comparisions unipedal(F-B) dynamic slalom tests between right and left leg.

\begin{tabular}{|c|c|c|c|c|c|}
\hline Sports & Unipedal (Forward-Backward) dynamic balance test & Mean (SD) & $\mathrm{t}$ & $\mathrm{df}$ & $\mathrm{p}$ \\
\hline \multirow{2}{*}{ Soccer } & Perimeter error of right leg (\%) & $95.05(41.20)$ & \multirow{2}{*}{-3.158} & \multirow{2}{*}{16} & \multirow{2}{*}{$0.006^{*}$} \\
\hline & Perimeter error of left leg (\%) & $154.14(8717)$ & & & \\
\hline \multirow{2}{*}{ Handball } & Perimeter error of right leg (\%) & $127.93(67.55)$ & \multirow{2}{*}{-1.102} & \multirow{2}{*}{15} & \multirow{2}{*}{0.295} \\
\hline & Perimeter error of left leg (\%) & $148.72(85.58)$ & & & \\
\hline
\end{tabular}

${ }^{*} \mathrm{p}<0.01$ 
Table 3. Comparisions leg mass between right and left leg.

\begin{tabular}{lllllll}
\hline & $\mathrm{N}$ & Sports & Mean (SD) & $\mathrm{t}$ & $\mathrm{df}$ & $\mathrm{p}$ \\
\hline \multirow{2}{*}{ Left leg } & & & & & & \\
\multirow{2}{*}{ Right leg } & 17 & Soccer & $8.42(1.01)$ & -2.97 & 30 & $0.006^{*}$ \\
& 15 & Handball & $9.54(1.10)$ & & & $0.002^{*}$
\end{tabular}

${ }^{*} \mathrm{p}<0.01$

In the literature it is stated that there was no significant difference in static balance among basketball, volleyball and handball tribal female players. But the other results of study that there were significant differences between basketball, volleyball, handball tribal female players in motor fitness (agility, co-ordination and dynamic balance) variables (36). In another research is pointed that gymnasts and soccer players did not differ in terms of static and dynamic balance. On the other hand, it is stated that basketball players displayed inferior static balance compared with gymnasts and inferior dynamic balance compared with soccer players. In addition, it is also stated that female basketball players demonstrated inferior static balance compared with gymnasts and inferior dynamic balance compared with soccer players. Spesific sensorimotor challenges, rather than general sport activity, appear to be important in developing optimal balance (12). It is pointed that basketball and soccer players had the similar features about the balance ability (17). It is stated that dancers had been certain standing balance abilities that were better than those soccer players (19). It is indicated that there is no difference between the judoists and dancers on their static balance rates while their eyes are opened, but when their eyes are closed the judoists have better static balance rates. With this data, it is stated that with a high level ability excercise including the prorioseptive effects develope both the performance and balance control. This situation shows the positive effects of the trainings on the sense-motor adaptation ability (29). Matsuda et al. (2008) examining C.o.P sway characteristics of both legs during 60 -sec static onelegged stance in athletes from different sports, showed that soccer players have a better one-legged stance than swimmers, basketball players and sedentary subjects (24).

Dynamic balance is necessary and effective in the fundamental technical movements of the both (handball and soccer) sports such as dribbling, throwing, kicking and faking. Handball and soccer players require maintain balance as they run at high speed, change direction and powerfully throw and kick the ball to pass or shoot (32). We also think that the probable reason of no significant difference on static and dynamic slalom balance rates and leg strenght scores, due to similar movements used often by both group, such as faking and changing direction.

Another finding is that it was found significant difference on unipedal (F-B) dynamic balance tests. When two groups were compared within each other, significant difference was found between right and left leg belongs to soccer players $\{t(15)=-3,158, p<$ $0,01\}$. Unipedal (F-B) dynamic balance test score of left leg was greater than right leg for soccer player, but, there is no significant differences for handball players $(p>0,05)$. It is mean that right leg's dynamic balance of soccer players is better than for left leg's $(p<0.05)$. We expected better stability of the nonpreferred leg because soccer players have to stabilize their stance leg in different positions for kicking the ball. This expectation could not be established by the results of our study. The result of the current research is incompatible with the results of Barone et al. (2011). It is stated that the soccer group showed better standing balance on the left leg than the sedentary group $(p<0.05)$. No other significant differences were observed within and among groups (sedantary, basketball players and windsurfers). The soccer players have a better standing balance on the nondominant leg because of soccer activity (8). On the other hand, it is stated that soccer player's left leg balance was more highly correlated than right leg balance with right (dominant) leg kicking accuracy. However, the same pattern of relations was not seen between single-leg balance and left (non-dominant) leg kicking accuracy (14).

We think that the first probable reason of one leg dynamic balance score due to all of the soccer players are dominantly using their right leg, so they mostly controlled the ball with their right leg. For this reason, this result which was found in our 
study, can be explained as right leg's dynamic balance is better than for supporting leg.

Second probable reason of one leg dynamic balance score due to training year and experience because of soccer players have only 4.64 training year. When training year is increased for soccer players, unipedal dynamic balance (forwardbackward) differences might not be occur in future studies. Because a good soccer players, it is essential to kick the ball well with both legs. When it is analysed the effects of postural control of the sensory-motor period, according to the branches of sports, it is understood that the senior players have better balance ability (6). Paillard et al. (2006), studied on the strategies and the postural performance during standing on one leg soccer players who are national and regional soccer players. As a result, it is analised in the lab conditions that the national soccer players have better postural performance and balance than regional soccer players. It is stated that experience effects postural performance during standing on one leg of soccer players. But even top-level players show bilateral differences when it is not possible to play the ball with their preferred leg (27). In another studies, the expertise on gymnastic has an effect on postural control during changing postural situation from two leg standing to one leg standing. It is stated that this effect is a result of the ability education and trainings $(45,44)$. On the other hand, it is indicated that the investigations of balance function and muscle response in amateur soccer players did not reveal significant differences between the preferred and nonpreferred leg (22).

Third probable reason of one leg dynamic balance score due to asimetric drills, adequate and strenght trainings. This wrong trainings may have applied by trainers, so young soccer players may have asymmetry unipedal dynamic balance test rates. Balance is not only important for the execution of complex technical gestures, but it is also connected to the overall athlete's strenght, as reported by (15). It is stated that there is a significant correspondence between given training programs and static and dynamic balance (38). Another research states that findings proved that the effect of 8-week combinational training (strenght and plyometric) on dynamic balance of teenage handball players. The highest effect in three groups (strenght, plyometric and combinational) were in three directions of posterior-internal, internal and posterior. In addition, it was indicated that as during achievement action in these directions we need
Hamstring muscle activity (35). It is stated that using a combinational plan (plyometric, technical, balance and strenght) can improve antreior-posterior balance (28). Another research was indicated that all three trainings (strenght, plyometric and combinational) improve dynamic balance among athlete students (34). Former studies have demonstrated asymmetries in muscle strenght, muscle activation, and muscle thickness between the two legs $(30,39)$. We compared mass of left and right leg between soccer and handball players. Significant differences were found favor of handball players $(p<0.05)$. In addition, we measured leg strenght of two leg without seperate each other by Takei dynamometer. There were no significant difference was found between handball and soccer players $(p>0.05)$. But there is significant difference was found unipedal balance test rates within soccer players $(p<0.05)$. If we had measured that lowerextremity muscles force for each leg such as hip adductor, knee or ankle extensor and flexor, this result may have explained clearly.

The last result of our study that there is no significant difference between left and right leg's balance of handball players $(p<0.05)$. Some researches are compatible with this result. Gribble et al. (2001) and Seiler et al.(2008) indicated that same result at their researches $(21,40)$. In addition Seiler et al. (2008) stated that one leg balance was not significantly improved after the intervention training (40). Vuillerme and Nougier (2004), compared gymnasts, soccer and handball players within each other. They determined that there is no difference between two groups on their "one leg" balance test (45). A certain tendency to better balance in the nonpreferred leg was observed, some authors did not demonstrated differences between dominant and nondominant extremities in athletes $(2,16,31)$. It is stated that none of the tests performed revealed statistically significant differences in balance ability between the preferred and the nonpreferred leg (22). Apart from this references we think that the probable reason of our study's result due to handball players's dominant legs are right like the soccer players, but their jumping legs are left. Because handball players who use right hands during play, usually jump their left leg. Therefore, asymmetries belongs to leg strenght of handball players might not have been occured.

A lot of factors which were indicated in our study, effect to static and dynamic balance such as motoric and anthropometric characteristics $(35,9)$, proprioseptive balance and visual clues $(13,20,4)$, 
explosive power (5), training programs (35), asymmetries in muscle strenght $(30,39)$, experince and training year $(45,6,27)$. If all this factors are searched, new and vary results which is different from our study's findings, might be found in future studies about static and/or dynamic balance rates between handball and soccer players. In future studies, if this factors are searched, the significant differences of static and/or dynamic balance rates between handball and soccer players might be found.

\section{Acknowlegment}

This study is supported and accepted by Presidency of the Marmara University Scientific Research and Projects with no (SAG-D-300409-0108).

\section{REFERENCES}

1. Anderson K, Behm DG. The impact of instability resistance training on balance and stability. Sports Med, 2005; 35: 43-53

2. Anderson C, Gillquist J. Instrumented testing for evaluation of sagittal knee laxity. Clinical Orthopaedics and Related Research, 1990; 256, 178-184

3. Arend S. Developing the substrates of skillful movement. Motor Skills: Theory into Practise, 1981; 4: 1-10.

4. Ashton Miller JA, Wojtys EM, Huston Lj, Fry-Welch D. Can Proprioception really be improved by exercises? Knee Surg Sports Traumatol Arthrosc, 2001; 9: 128-136.

5. Atilgan Erkut O. Effects of tramboline training on jump, leg strenght, static and dynamic balance of boys. Science of Gymnastics Journal, 2013; 5(2): 15-25.

6. Balter SGT, Stokroos RJ, Akkermans E, Kingma H. Habituation to galvanic vestibular stimulation for analysis of postural control abilities in gymnasts. Neurosci Lett, 2004; 366: $71-75$

7. Barfield, W. R. Effects of selected kinematic and kinetic variables on instep kicking with dominant and nondominant limbs. Journal of Human Movement Studies, 1995; 29: 251272.

8. Barone R, Macaluso F, Traina M,Leonardi V, Farina F, Di Felice V. Soccer players have a better standing balance in nondominant one-legged stance. Open Access Journal of Sports Medicine, 2001; 2: 1-6.

9. Baydil B. Eurofit testleri ile 12-14 yas grubu erkek öğrencilerin fiziksel uygunluk normlarinin araştirilmasi. Ahi Evran Universitesi Kirsehir Egitim Fakultesi Dergisi (KEFAD), 2006; 7(2): 79-87.

10. Beraud P, Gahery Y. Posturo- kinetic effects on kicking movements of a lack of initial ground support under the moving leg. Neuroscience Letters, 1997; 226: 5-8.

11. Beraud P, Gahery Y. Relationships between the force of voluntary leg movements and the associated postural adjustments. Neuroscience Letters, 1995; 194: 177-180.

12. Bressel E, Yonker J.C, Kras J, Heath EM. Comparision of static and dynamic balance in female collegiate soccer, basketball and gymnastics athletes. Journal of Athletic Training, 2007; 42(1): 42-46
13. Carolyn A, Emery J, Cassidy D, Terry P, Klassen Rhonda J, Rosychuk, Brian H. Effectiveness of a home-based balancetraining program in reducing sports-related injuries among healthy adolescents: a cluster randomized controlled trial. CMAJ, 2005; 172(6): 749-754.

14. Chew-Bullock Tracey SY, Anderson DI, Hamel KA, Gorelick ML, Wallace SA, Sidaway B. Kicking performance in relation to balance ability over the support leg. Human Movement Science, 2012; 31: 1615-1623.

15. Cowley HR, Ford KR, Myer GD, Kernozek TW, Hewett TE. Differences in neuromuscular strategies between landing and cutting tasks in female basketball and soccer athletes. Journal of Athletic Training, 2006; 41: 67-73.

16. Edixhoven P, Huiskes R, De Graaf R. Anteroposterior drwer measurements in the knee using an instrumented test device. Clinical Orthopaedics and Related Research, 1989; 247: 232242.

17. Erkmen N, Suveren S, Göktepe S.A, Yazıcıoğlu K. The comparison of balance performance who are in different branches. Spormetre Physical Education and Sport Science Journal, 2007; 3: 115-122.

18. Gardner ER, Martin JH, Jessell TM. The bodily senses. In: Kandel ER, Schwartz JH, Jessell TM, (Ed). Principles of neural science, 4th ed. New York: McGraw-Hill, 2000, pp. 430-449.

19. Gerbino GP, Griffin ED, Zurakowski D. Comparison of standing balance between female collegiate dancers and soccer players. Gait \& Posture, 2007; 26(4): 501-507.

20. Gioftsidou A, Malliou P, Sofokleous P, Pafis G, Beneka A, Godolias $\mathrm{G}$. The effects of balance training on balance ability in handball players. Exercise and Quality of Life, 2012; 4(2): 15-22.

21. Gribble PA, Hertel J, Piegaro AB. Predictors for performance of dynamic postural using the Star Excursion Balance Test. Journal of Athletic Training, 2001; 36: 2(Supplement): S-77.

22. Gstöttner M, Neher A, Scholtz A, Millonig M, Lembert S, Raschner C. Balance ability and muscle response of the preferred and nonpreferred leg in soccer players. Motor Control, 2009; 13: 218-231.

23. Lion A, Gauchard GC, Deviterne D, Perrin PhP. Differentiated influence of off-road and on-road cycling practice on balance control and the related-neurosensory organization. J Electromygr Kinesio, 2009; 19: 623-30.

24. Matsuda S, Demura S, Uchiyama M. Centre of pressure sway characteristics during static one-legged stance of athletes from different sports. J Sports Sci, 2008; 26(7): 775-9.

25. Olmsted LC, Carcia CR, Hertel J, Shultz SJ. Efficacy of the Star Excursion Balance Tests in detecting reach deficits in subjects with chronic ankle instability. Journal of Athletic Training, 2002; 37: 501-506.

26. Orchard J. Is there a relationship between ground and climatic conditions and injuries in football? Sports Med, 2002; 32: 419-432.

27. Paillard T, Noe F, Riviere T, Marion V, Montaya R, Dupui P. Postural Performance and Strategy in the unipedal stance of soccer players at different levels of competition. Journal of Athletic Training, 2006; 41(2): 172-176.

28. Paterno MV, Myer GD, Ford KR, Hewett TE. Neuromuscular training improves single-limb stability in young female athletes. J. Orthop Sports Phys ther, 2004: 34(6): 305-16. 
29. Perrin D. Deviterne F. Hugel C. Perrot. Judo, better than dance, develops sensorimotor adaptabilities involved in balance control. Gait Posture, 2002; 15: 187-194.

30. Rahnama N, Lees A, Bambaecichi E. Comparison of muscle strenght and flexibility betweenthe preferred and nonpreferred leg in English soccer players. Ergonomics, 2005; 48(11-14): 1568-1575.

31. Rangger C, Daniel DM, Stone ML, Kaufman K. Diagnosis of an ACL disruption with KT-1000 arthrometer measurements. Knee Surgery Sports Traumatology Arthroscopy, 1 (1), 60-66.

32. Rannou F, Prioux J, Zouhal H, Gratas-Delamarche A, Delamarche P, Physiological profile of handball players. J Sports Med Phys Fitness, 2001; 41(3): 349-53.

33. Ross SE, Guskiewicz KM. Examination of static and dynamic postural stability in individuals with functionally stable and unstable ankles. Clinical Journal of Sport Medicine, 2004; 14: 332-338.

34. Sadeqi H, Hamdollah H, Rostamkhani H, Bashiri M. The effect of six-weeks strenght, plyometric and combinational trainings (strenght and plyometric) on dynamic balance of male athlete students. A research on sport science: 1988, 111123.

35. Salehzadeh K, Karimiasl A, Borna S, Shirmohammadzadeh M. The effects of 8-week plyometric and combinational trainings on dynamic balance of teenage handball players. J Basic Appl Sci Res, 2011; 1(12): 3316-3321.

36. Santoshi J, Bahadur Arvind S. Comparison of selected motor fitness variables amog basketball, volleyball and handball tribal female players. Golden Research Thoughts, 2011; 1(6, Special section): $\mathrm{p} 1$.

37. Saygın Ö, Öztürk AÖ. The effect of twelve week aerobic exercise programme on health related physical fitness components and blood lipids in obese girls. African Journal of Pharmacy and Pharmacology, 2011; 5(12): 1441-1445.

38. Schneiders AG, Sullivan SJ, Handcock P, Gray A, McCrory PR. The effect of exercise on dynamic and static balance. Scandinavian Journal of Medicine \& Science in Sports, 2012; 22(1): 85-90.

39. Schuepfer N, Lembert S, Raschner C, Platzer HP, Niederkofler A, Patterson C. Bilateral differences in electromyographic responses of thigh and knee muscles during repeated maximal isokinetic knee extension and flexion in soccer players. Abstract Band of the 5th International Conference on Strenght Training, Odense, 2006.

40. Seiler S, Saeterbakken A. A unique core stability training program improves throwing velocity in female high school athletes. Medicine and Science in Sports and Exercise, 2008; 40(5): 25

41. Şimşek D, Ertan H. Postural kontrol ve spor: spor branşlarına yönelik postural sensör-motor stratejiler ve postural salınım. Spormetre Beden Eğitimi ve Spor Bilimleri Dergisi, 2011, 9(3): 81-90.

42. Siu Ming Fong S, Wai Nam Tsang W, Yin Fat Ng G. Practicing taekwondo may improve proprioception, leg strength and balance International Sport Med Journal, June 2013; 14(2): 44-52. Available at URL: http://www.ismj.com

43. Tsang WWN, Hui-Chan CWY. Effect of 4- and 8-wk intensive tai chi training on balance control in the elderly. Med Sci Sports Exerc, 2004; 36: 648-657.

Turk ل Sport Exe 2014; I6(I): 47-54

(ㄱ 2014 Department of Physical Education and Sport, Selcuk University
44. Vuillerme N, Danion F, Marin L, Boyadjian A, Prieur JM, Weise I, Nougier V. The effect of expertise in gymnastics on postural control. Neurosci Lett, 2001; 303: 83-86.

45. Vuillerme N, Nougier V. Attentional demand for regulating postural sway: the effect of expertise in gymnastics. Brain Research Bulletin, 63: 161-165, 2004.

46. Wickstrom RL. Fundamental motor patterns (3rd ed.). Philadelphia: Lea and Febiger, 1983.

47. Williams LR, Walmsley A. Response timing and muscular coordination in fencing: a comparison of elite and novice fencers. J Sci Med Sport, 2000; 3: 460-75.

48. Williams HG. Perceptual and motor development. Englewood Cliffs, NJ: Prentice-Hall, 1983.

49. Yiou E, Do MC. In a complex sequential movement, what component of the motor program is improved with intensive practice, sequence timing or ensemble motor learning? Exp Brain Res, 2001; 137: 197-204.

http://www.tecnobody.it (last access date: 27 January 2011). 